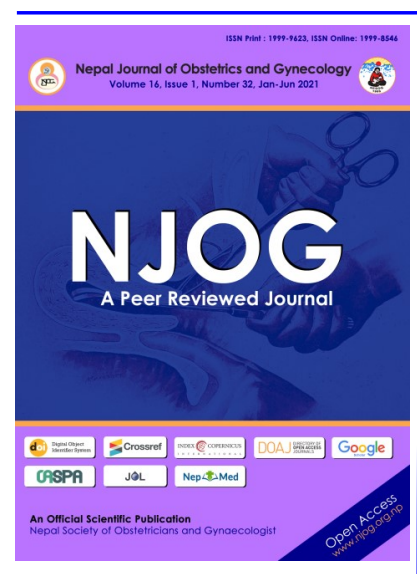

CORRESPONDENCE

Dr Monica Gurung

Department of Obstetrics and Gynaecology

$\mathrm{B}$ and $\mathrm{C}$ Medical College Teaching Hospital,

Birtamode, Jhapa, Nepal

Email: monicagurung717

@gmail.com;

Phone: +977-9849365619

Received: December15, 2021

Accepted: April 1, 2021

\section{Citation:}

Gurung M, Baral G. Peripartum hysterectomy at a tertiary center. Nep J Obste Gynecol. 2021;16(32):88-

91. DOI: https://

doi.org/10.3126/

njog.v16i1.37613

\title{
Peripartum hysterectomy at a tertiary center
}

\author{
Monica Gurung, Gehanath Baral \\ Department of OBGYN, Paropakar Maternity and Women's Hospital, \\ Kathmandu
}

\section{ABSTRACT}

Aims: To find out the incidence, indications, complication of emergency peripartum hysterectomy in a tertiary care center.

Methods: This was a retrospective study conducted over a period of 18 months from April 2017 to October 2018 at Paropakar Maternity and Women's Hospital in Kathmandu. Data were obtained from the operation theater register and record section.

Results: Out of 30917 deliveries in 18 months 18 had lifesaving emergency peripartum hysterectomy ( 0.58 per 1000 deliveries). The most common indication being morbidly adherent placenta/placenta previa $(8 ; 44 \%)$ followed by ruptured uterus $(5 ; 28 \%)$, uterine atony $(4 ; 22 \%)$. The most common risk factor is attributed to previous cesarean section $(11 ; 61 \%)$ followed by abnormal placentation $(7 ; 39 \%)$. Most common morbidity was febrile morbidity followed by wound infection and bladder injury.

Conclusion: Abnormal placentation and past cesarean section contributed to be the major indication of peripartum hysterectomy.

Keywords: abnormal placentation, cesarean section, peripartum hysterectomy

\section{INTRODUCTION}

Hysterectomy is one of the common gynaecological procedures however in obstetrics it is a rare and lifesaving procedure. The first successful cesarean hysterectomy was done in 1876 by Eduardo Porro in which both the mother and baby survived. ${ }^{1}$ Centuries have passed, obstetrician are still adherent to this complex surgical procedure which needs years to excel and are learning to make a wise timely decision in order to decrease maternal mortality and morbidity.

The incidence varies from 0.248.9/1000 deliveries. ${ }^{2}$ Most of the cases are Emergency Peripartum Hysterectomy (EPH) which is performed at the time of cesarean section or following vaginal delivery for abnormal placentation, uterine atony and ruptured uterus whereas elective are reserved for preoperatively diagnosed morbidly adherent placenta, pregnancy with cervical cancer and huge fibroid. ${ }^{3}$ Earlier the most common indication for EPH was uterine atony but these days it is due to abn- ormal placentation. ${ }^{4,5}$ This rise in abnormal placentation has been seen in parallel to rising cesarean section. ${ }^{6,7}$

This study was undertaken to find out the incidence of EPH, indications and its morbidities in our center.

\section{METHODS}

This is a hospital based retrospective study conducted over a period of 18 months from April 2017 to October 2018. Approval for the study was taken from the ethical committee of the hospital. The data were collected from the record section and records maintained at Operation Theater. The variables studied were age, parity, risk factors, conservative measures, morbidity, duration of surgery and anesthetic management. Descriptive data were generated as percentage and mean.

\section{RESULTS}

There were a total of 30917 deliveries among which 18 cases had EPH so it was $0.58 / 1000$ deliveries. Eight were done during cesarean section and 5 for ruptured uterus. Morbidly adherent placenta and placenta praevia $(8 ; 44 \%)$ 
were the common indication for EPH followed by ruptured uterus $(5 ; 28 \%)$, uterine atony $(4 ; 22 \%)$ and one case of bleeding disorder. There was no elective peripartum hysterectomy during the study period. [Table-1]

Table-1: Incidence of EPH according to mode of delivery

\begin{tabular}{lccc}
\hline $\begin{array}{l}\text { Mode of } \\
\text { delivery }\end{array}$ & $\begin{array}{c}\text { Total } \\
\text { delivery }\end{array}$ & EPH & EPH/1000 \\
\hline $\begin{array}{l}\text { Cesarean } \\
\text { Section }\end{array}$ & 7520 & 13 & 1.73 \\
$\begin{array}{l}\text { Vaginal } \\
\text { delivery }\end{array}$ & 19324 & 5 & 0.26 \\
\hline
\end{tabular}

The average age of women who underwent EPH was 28.9 (range: 19-36) years. The mean weeks of gestation was 36w3d (range: $30 \mathrm{w}-40 \mathrm{w} 6 \mathrm{~d}$ ). There were $16(94.44 \%)$ multigravida, 1 grand-multi and 1 primi. The identified common risk factors were past cesarean section ( 8 single and three twice) and morbidly adherent placenta/ placenta previa $(7 ; 39 \%)$.

Primary medical and conservatory measures were applied in all cases prior to proceed for hysterectomy. Among 5 case of vaginal delivery, 4 received uterine plus compression suture and uterine artery ligation in one case; and one had internal artery ligation. Seven cased had total hysterectomy and subtotal in 11 cases. EPH is associated with increased morbidities. [Table-2]

Table-2: Post-operative morbidities

\begin{tabular}{ll}
\hline Infective/febrile morbidity & $\mathrm{N}$ \\
\hline Febrile morbidity & 7 \\
Wound infection/ Dehiscence & 3 \\
Urinary tract infection & 1 \\
Septicemia & 1 \\
Pneumonitis/ Pneumonia & 1 \\
\hline
\end{tabular}

Despite these measures, two maternal deaths occurred who had vaginal delivery. Infective febrile morbidity occurred in 13 cases, 3 had bladder injury and one DIC. Average anaesthesia time (for 11 general, 3 spinal, 3 spinal to general and one intravenous to general anaesthesia) was 149 minutes (range: 1-4 hours). Hospital stay is not related with only EPH and includes from antepartum observation till discharge; so it averaged 16.9 (range: 1-44) days. ICU stay averaged 4.5 (range: 1-16) days. Blood transfusion was 7.7units in average (range: 213) with average blood loss of 3150 (range: 10005000) $\mathrm{ml}$.

\section{DISCUSSION}

There has been varying incidence of peripartum hysterectomy in different centers in different parts of the world. In developed countries like Australia and New Zealand it was $0.85 / 1000$ and $0.4 / 1000$ deliveries respectively whereas in a center in India it was reported to be as high as $6.9 / 1000$ deliveries. ${ }^{8-10}$ In our center it was $0.58 / 1000$ deliveries, similar rates were seen in other tertiary centers in Nepal. ${ }^{5,11}$ There has been increased EPH in women who underwent cesarean section compared to the vaginal delivery. ${ }^{12}$ It was $1.73 / 1000$ deliveries in cesarean section and 0.26/1000 deliveries among vaginal delivery.

There has been a shift in the indication for EPH. Earlier it was uterine atony. ${ }^{13}$ Currently, worldwide we can see the most common indication being abnormal placentation. ${ }^{14}$ In our center the most common indication for EPH was abnormal placentation in $44.0 \%$. Similar indication was observed in India which contributed for $43.1 \%$ and in Korea $54.3 \%$ of cases. ${ }^{15,16}$

This shift has been closely related to the rising cesarean section worldwide. Both cesarean section and prior cesarean section were strong risk factors for emergency peripartum hysterectomy with higher risks conferred for each additional cesarean section. Although WHO states $10-15 \%$ of CS rate is optimal but in our center its $30 \%$ whereas in private centers in Nepal it is as high as $81 \%{ }^{17,18}$ This is a global problem, even developed countries are facing the same so the increased risk of emergency peripartum hysterectomy should be factored into the decision of whether to proceed with cesarean delivery, particularly for women who desire more children. ${ }^{19}$

The second common indication being ruptured uterus as $28 \%$. Still in some centers in Nepal and Nigeria it contributes to be the major indication of EPH accounting for $65.5 \%$ (21/19,539 deliveries) and $73.3 \%$ (22/7532 deliveries) respectively. The main reason being unbooked cases, obstructed labour and previous cesarean section. ${ }^{20,21}$ Whereas in some center, in Nepal and Egypt the primary indication is uterine atony. ${ }^{11,22}$

EPH is a massive challenge to the obstetrician and anesthesiologist. It's associated with massive blood loss so requires prompt measures to balance the haemodynamics. There's prolonged operating time with mean duration of 149 minutes. In Korea the mean operative time was 189 minutes. ${ }^{16}$ It needs expert surgical skill to perform peripartum hysterectomy, so the surgeon decides whether to perform subtotal or total hysterectomy. In our center there were $11(61.11 \%)$ subtotal hysterectomy which might be attributed to surgeon's competency, shorter operating time and better control of haemorrhage compared to total hysterectomy. Similar practice was seen in Pakistan and Saudi Arabia. $^{23,24}$

With peripartum hysterectomy, its associated with serious morbidities. Febrile morbidity as $27 \%$ was 
most common followed by wound dehiscence and bladder injury $20 \%$. Similar finding was observed in a tertiary center in India. ${ }^{10}$ Apart from febrile morbidity bladder injury is the most common morbidity in other centers as well. ${ }^{22,25}$ Mortality from peripartum hysterectomy is more than 25 times that of hysterectomy performed outside of pregnancy. ${ }^{14}$ Peripartum hysterectomy is also associated with increased financial burden to the health care cost and psychological trauma. ${ }^{26,27}$

In modern obstetrics, uterus preserving procedures are proven to be promising. The novel technique like the "Triple P Procedure" (Perioperative placental localization and delivery of the fetus via transverse uterine incision above the upper border of placenta, Pelvic devascularization, Placental non separation with myometrial excision and reconstruction of the uterine wall) and Uterine Artery Embolization can be embraced in our practice as well. ${ }^{28-31}$

\section{CONCLUSIONS}

The primary indication of EPH is abnormal placentation with previous cesarean section and the cesarean section is associated with increased morbidity.

\section{REFERENCES}

1. Zouhair O. Amarin. Peripartum Hysterectomy. http://dx.doi.org/10.5772/60942

2. Machado LS. Emergency peripartum hysterectomy: Incidence, indications, risk factors and outcome. N Am J Med Sci. 2011;3:358-61.

3. Akker TV, Brobbel C, Dekkers OM, Bloemenkamp KWM. Prevalence, Indications, Risk Indicators, and Outcomes of Emergency Peripartum Hysterectomy Worldwide: A Systematic Review and Meta-analysis. Obstet Gynecol. 2016;128 (6):1281-94.

4. Yalinkaya A, Güzel AI, Kangal K. Emergency Peripartum Hysterectomy: 16-year Experience of a Medical Hospital. J Chin Med Assoc. 2010;73 (7):360-3.

5. Bista KDB. Changing Trends in Peripartum hysterectomy at Tertiary Institute in Nepal. J Ins Med. 2014;36(1):18-23.

6. Sahin S, Guzin K, Eroğlu M, Kayabasoglu F, Yaşartekin MS. Emergency peripartum hysterectomy: our 12-year experience. Arch Gynecol Obstet. 2014;289(5):953-8.

7. Karayalçın, R, Özcan S, Özyer S, Mollamahmutoğlu L, Danısman N. Emergency peripartum hysterectomy. Arch Gynecol Obstet. 2011;283:723-7.

8. Awan N, Bennett MJ and Walters WA. Emergency peripartum hysterectomy: a 10-year review at the Royal Hospital for Women, Sydney.
Aust N Z J Obstet Gynecol. 2011;51(3):210-5.

9. Wong TY. Emergency peripartum hysterectomy: a 10-year review in a tertiary obstetric hospital. Journal of the New Zealand Medical Association. 2011;124(1345):34-9.

10. Sharma B, Sikka P, Jain V, Jain K, Bagga R, Suri V. Peripartum hysterectomy in a tertiary care hospital: Epidemiology and outcomes. J Anaesthesiol Clin Pharmacol. 2017;33(3):3248.

11. Singh A, Shrestha S, Pradhan A. Nine years review of emergency peripartum hysterectomy at tertiary care university teaching hospital. J Patan Acad Health Sci. 2016;3(1):23-6.

12. Kashani E, Azarhoush R. Peripartum hysterectomy for primary postpartum hemorrhage: 10 years evaluation. Eur J Exper Biol. 2012;2 (1):32-6.

13. Knight M. UKOSS. Peripartum hysterectomy in the UK: management and outcomes of the associated haemorrhage. BJOG. 2007;114 (11):1380-7.

14. Wright JD, Devine P, Shah M, Gaddipati S, Lewin SN, Simpson LL,et al. Morbidity and mortality of peripartum hysterectomy. Obstet Gynecol. 2010;115(6):1187-93.

15. Patalay KA, Vijaya K, Ratna PD. Incidence and causes of Peripartum Hysterectomy - A Prospective study. Asian Pac J Health Sci. 2016;3(2):170-78.

16. Lee IH, Son JH, Shin YC, Byun JH, Yoon HJ, Jee YS. Anesthetic review of emergency peripartum hysterectomy following vaginal and cesarean delivery: a retrospective study. Kor J Anesthesiol. 2012;63(1):43-7.

17. WHO Statement on Cesarean Section Rates [internet]. 2015 [cited 8 August 2018]. Available from http://apps.who.int/iris/bitstream/ handle/10665/161442/

WHO_RHR_15.02_eng.pdf?sequence=1

18. Laxmi T, Goma DNS, Kumariniraula H, Roshnitui T, Binod A. Rising Cesarean Section Rates in Nepal: Question of safety and Integrity on Obstetric Emergency Practice. J Gynecol Women Health. 2017;7(4):1-4.

19. de la Cruz CZ, Thompson EL, O'Rourke K, Nembhard WN. Cesarean section and the risk of emergency peripartum hysterectomy in high -income countries: a systematic review. Arch Gynecol Obstet. 2015;292(6):1201-15.

20. Basnet P, Rai R, Agrawal A, Thakur A, Shrestha R. Peripartum Hysterectomy and Analysis of Risk Factors. Nep J Obstet Gynae- 
Gynaecol. 2018;12(1):46-9.

21. Ohonsi AO, Olayinka HT. Emergency Peripartum Hysterectomy in a Developing Country. J Obstet Gynaecol Can. 2012;34(10):954-60.

22. Abbas AM, Abdelbadee AY, Amin MT, Abdelrahman RM, Tolba SM, Abdelkarim AR, et al. Emergency peripartum hysterectomy in a tertiary hospital in Upper Egypt: six years analysis. Int J Reprod Contracep Obstet Gynecol. 2016;5(4):953-8.

23.Nisar N, Sohoo NA. Emergency Peripartum Hysterectomy: Frequency, Indications and Maternal Outcome. J Ayub Med Coll Abbottabad. 2009;21(1):48-51.

24.Zia S, Ratique M, Rizwan A, Khan T, AlShamrani A. Maternal outcome in Emergency Peripartum Hysterectomy: Minimizing the Risks. J South Asian Feder Obstet Gynaecol. 2013;5(3):91-5.

25. Carvalho JF, Torres S, Costa F, Carmo O. Emergency Peripartum Hysterectomy: A10YearReview. International Scholarly Research Network ISRN Emergency Medicine. 2012; Article ID 721918, 7.

26. Achana FA, Fleming KM, Tata LJ, Sultan AA, Petrou S. Peripartum hysterectomy: an economic analysis of direct healthcare costs using routinely collected data. $\mathrm{Br} \mathrm{J}$ Obstet Gynaecol. 2018;125(7):874-83.
27. de la Cruz CZ, Coulter ML, O'Rourke K, Alio PA, Daley EM, Mahan CS. Women's Experiences, Emotional Responses, and Perceptions of Care After Emergency Peripartum Hysterectomy: A Qualitative Survey of Women from 6 Months to 3 Years Postpartum. BIRTH. 2013;40(4):256-63.

28. Tskhay VB, Yametov PK, Yametova NM. The use of modified triple-p method with adherent placenta long- term results. MOJ Womens Health. 2017;4(2):30-32.

29. Wei Y, Cao Y, Yu Y, Wang Z. Evaluation of a modified "Triple-P" procedure in women with morbidly adherent placenta after previous caesarean section. Arch Gynecol Obstet. 2017;296:737-43. https://doi.org/10.1007/ s00404-017-4447-0

30. Juneja SK, Tandon P, Mohan B, Kaushal S. A change in the management of intractable obstetrical hemorrhage over 15 years in a tertiary care center. Int J Appl Basic Med Res. 2014;4 (Supplement 1):17-9.

31. Vandenberghe G, Guisset M, Janssens I, Leeuw VV, Roelens K, Hanssens M, et al. A nationwide population-based cohort study of peripartum hysterectomy and arterial embolisation in Belgium: results from the Belgian Obstetric Surveillance System. BMJ Open. 2017;7:e016208. doi:10.1136/ bmjopen-2017016208 